\title{
Characterization of Olive-Associated Fungi of Cultivars with Different Levels of Resistance to Anthracnose ${ }^{+}$
}

\author{
Hamdi Bahri, Vitor Ramos (D), Diogo Mina, José A. Pereira (D) and Paula Baptista *(D) \\ Centro de Investigação de Montanha (CIMO), Instituto Politécnico de Bragança, Campus de Santa Apolónia, \\ 5300-253 Bragança, Portugal; hamdi.bahri07@gmail.com (H.B.); vramos@ipb.pt (V.R.); jdmina@ipb.pt (D.M.); \\ jpereira@ipb.pt (J.A.P.) \\ * Correspondence: pbaptista@ipb.pt \\ † Presented at the 1st International Electronic Conference on Plant Science, 1-15 December 2020; \\ Available online: https://iecps2020.sciforum.net/.
}

check for updates

Citation: Bahri, H.; Ramos, V.; Mina, D.; Pereira, J.A.; Baptista, P.

Characterization of Olive-Associated Fungi of Cultivars with Different Levels of Resistance to Anthracnose. Biol. Life Sci. Forum 2021, 4, 60. https://doi.org/10.3390/ IECPS2020-08878

Academic Editor: Yoselin Benitez-Alfonso

Published: 3 December 2020

Publisher's Note: MDPI stays neutral with regard to jurisdictional claims in published maps and institutional affiliations.

Copyright: (c) 2020 by the authors. Licensee MDPI, Basel, Switzerland. This article is an open access article distributed under the terms and conditions of the Creative Commons Attribution (CC BY) license (https:// creativecommons.org/licenses/by/ $4.0 /)$.

\begin{abstract}
Olive anthracnose, caused by Colletotrichum spp., is one of the most damaging fruit diseases in olive crops worldwide. Their control is very difficult and relies mostly in the use of copper-based fungicides. The plant-associate fungal community has been increasingly recognized for playing an important role in plant health and fitness. Thus, in this work, the olive-associated fungi of cultivars with different levels of resistance to anthracnose were characterized to identify potential protecting fungi for a sustainable strategy of biocontrol. A culture-dependent approach was used to assess both epiphytic and endophytic fungal communities of leaves from the olive cultivars Madural (susceptible to anthracnose) and Cobrançosa (moderately tolerant), and the isolates obtained were identified by rRNA sequencing. Overall, the Ascomycota phylum and Aureobasidium genus were the most dominant, being epiphytes that are significantly more diverse and abundant than endophytes. Host plant (at cultivar level) had a negligible effect on the composition of the fungal communities of the leaves. Future research needs to highlight the most prominent taxa arising from different cultivars and to decipher these complex interactions between plants and fungi and assess their role in plant health.
\end{abstract}

Keywords: Olea europaea; fungal diversity; endophyte; epiphyte; biocontrol; Colletotrichum spp.

\section{Introduction}

Olive tree (Olea europaea L. subsp. europaea var. europaea) cultivation is ancient, and its history merges with that of the Mediterranean basin [1]. Indeed, its origin must have taken place in the Middle East, near the border between Turkey and Syria [2]. Not surprisingly, olive tree cultivation still has great economic, social and ecological importance in the Mediterranean region, where $95 \%$ of world's olive groves are concentrated [3]. However, several pests and diseases cause significant yield and quality losses to table olive and olive oil production, the main products from this crop. Among them, olive anthracnose, caused by several species of the fungal genus Colletotrichum, is the most damaging disease [1,4]. The disease has been reported in all olive-growing regions worldwide, where it can have high economic impact, especially in years with environmental conditions favourable to the development of the disease (i.e., high humidity) and in groves with disease-susceptible varieties [5,6]. For instances, in Italy, Spain and Portugal, yield losses due to olive anthracnose often attain $80-100 \%$ [1,5]. Its control is very difficult and none of the available control measures are effective or safe enough [4]. For instance, fungicide residues are consistently found in oil and fruits from crops treated with copper-based fungicides [7]. To circumvent these problems, some efforts have been made to manage this disease in a more effective and environmentally friendly manner [4]. One promising approach can rely on the exploitation of endophytes that naturally colonize the internal plant tissues of olive trees. To support this approach, there is evidence showing that plants and their associated endophytes 
interact and modulate traits in host plants [8]. Within this context, the manipulation of endophytes to improve positive interactions with the host plant in order to modify resistance traits could be a promising tool for the control of olive anthracnose. Indeed, several endophytic fungal species isolated from olive tree leaves [9] or olive fruits [10] showed to inhibit significantly the growth of the anthracnose causal agent Colletotrichum acutatum, under in vitro conditions. In this work, endophytic diversity and host plant health as well as of the influence of crop management practices on endophytic composition and the underlay effect to host plant protection against diseases. This work aims to recognize taxa commonly found on the fungal community of two important Portuguese cultivars, which are differently susceptible to olive anthracnose. The results obtained will be useful to exploit the potential in using a specific olive tree genotype (at cultivar level) to model and manage host-endophyte interactions, in order to reduce the incidence/severity of anthracnose disease.

\section{Experiments}

\subsection{Sample Collection}

Leave samples were collected from an organic olive orchard located in Vale de Telhas, Mirandela (Northeast of Portugal, $41^{\circ} 36^{\prime} 29.0^{\prime \prime} \mathrm{N} 7^{\circ} 13^{\prime} 27.6^{\prime \prime} \mathrm{W}$ ). This is a mountainous region, with altitudes ranging between 300 and $500 \mathrm{~m}$, displaying a Mediterranean climate, with cold and rainy winters and long, hot, and dry summers. Two varieties with different susceptibilities to anthracnose were selected, the cultivars Cobrançosa (moderately tolerant) and Madural (susceptible). For each cultivar, branches from five trees were transported to the laboratory in an icebox and stored at $4{ }^{\circ} \mathrm{C}$ until the isolation of the epi- and endophytic fungi has started.

\subsection{Fungal Isolation and Enumeration}

From each branch, five leaves were randomly selected and used to isolate the epiphytes and endophytes. To isolate the fungal epiphytes, about $1 \mathrm{~g}$ of leaves was added to $9 \mathrm{~mL}$ of sterile potassium phosphate buffer $\mathrm{pH}$ 7.0. This suspension was placed on a rotary shaker (200 rpm) for $60 \mathrm{~min}$, at room temperature, to dislodge microorganisms from the leaves surface. Aliquots of $1 \mathrm{~mL}$ of the resulting microbial suspensions were separately plated in triplicate on Potato Dextrose Agar (PDA, Difco, Franklin Lakes, NJ, USA) medium. Plates were incubated at $25 \pm 2{ }^{\circ} \mathrm{C}$ in the dark and were observed daily for microbial growth and colony counting. Endophytic fungi were isolated from the same leaves used to isolate the epiphytes. After removing the epiphytes by surface disinfection through a procedure described in Martins et al. [11], each leaf was cut into segments (ca. $5 \times 5 \mathrm{~mm}$ ), which were transferred to fresh PDA medium. To validate the surface sterilization procedure, the surface of the sterilized plant tissues was imprinted onto a new, fresh PDA plate. Fungal colonies were subcultured until pure epi- or endophytic cultures were obtained.

\subsection{Fungal Identification}

After morphological characterization, isolates were grouped by fungal colony types as described in Gomes et al. [12]. A representative isolate of each morphotype was then selected for molecular-based identification using the internal transcribed spacer (ITS) region of the nuclear ribosomal DNA (ITS1, 5.8S, ITS2). Mycelia and/or spores from each isolate were harvested, and the total genomic DNA extracted using the REDExtract-

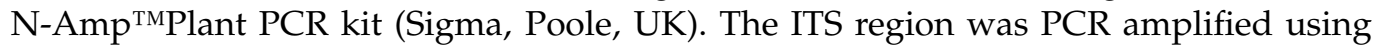
the primer sets ITS1/ITS4, ITS5/ITS4 or ITS2/ITS4 [13]. The amplified products were sequenced by Macrogen Europe B.V. (Amsterdam, The Netherlands). The obtained raw DNA sequences were analysed and edited with the software Geneious 8.1.8. (Auckland, New Zealand). In order to identify the fungal isolates, the default $(n r / n t)$ and the curated Fungi RefSeq ITS NCBI [14] databases were used for nucleotide BLAST searches. In accordance to $\mathrm{Vu}$ et al. [15], for sequence identities $>99.6 \%$ species names were accepted; for sequence identities between $94.3 \%$ and $99.5 \%$ only the genus was accepted; and for 
sequence identities ranging between $88.5-94.2 \%$ and $81.2-88.4 \%$ the family and order names were retained, respectively. Pure cultures of each identified isolate were preserved and deposited in the CIMO culture collection, at the Polytechnic Institute of Bragança.

\section{Results}

\section{General Description of the Fungal Community}

The isolation and characterization of fungi from the olive leaves allowed to distinguish 153 taxa, mostly belonging to the Ascomycota (relative abundance of $89 \%$ ) phylum (Figure 1). The Basidiomycota represented 3\% of the entire community, while an unassigned Mucoromycota species $(0.4 \%)$ was found to be present in both endophytic and epiphytic communities. Twenty-six of the isolates have been identified to the species level, while the remaining could not be assigned at this taxonomic rank, nor even at the genus level (63 isolates). The identified species belonged to 26 genera and 20 families, all from the Ascomycota (20 genera) and the Basidiomycota (6) phyla. The more abundant class was Dothideomycetes $(41.2 \%)$, followed by Eurotiomycetes (34.8\%) (Figure 1), while at the order level, Phaeomoniellales (28.1\%), Pleosporales (22.4\%) and Dothideales $(11.9 \%)$ were the most abundant taxa.

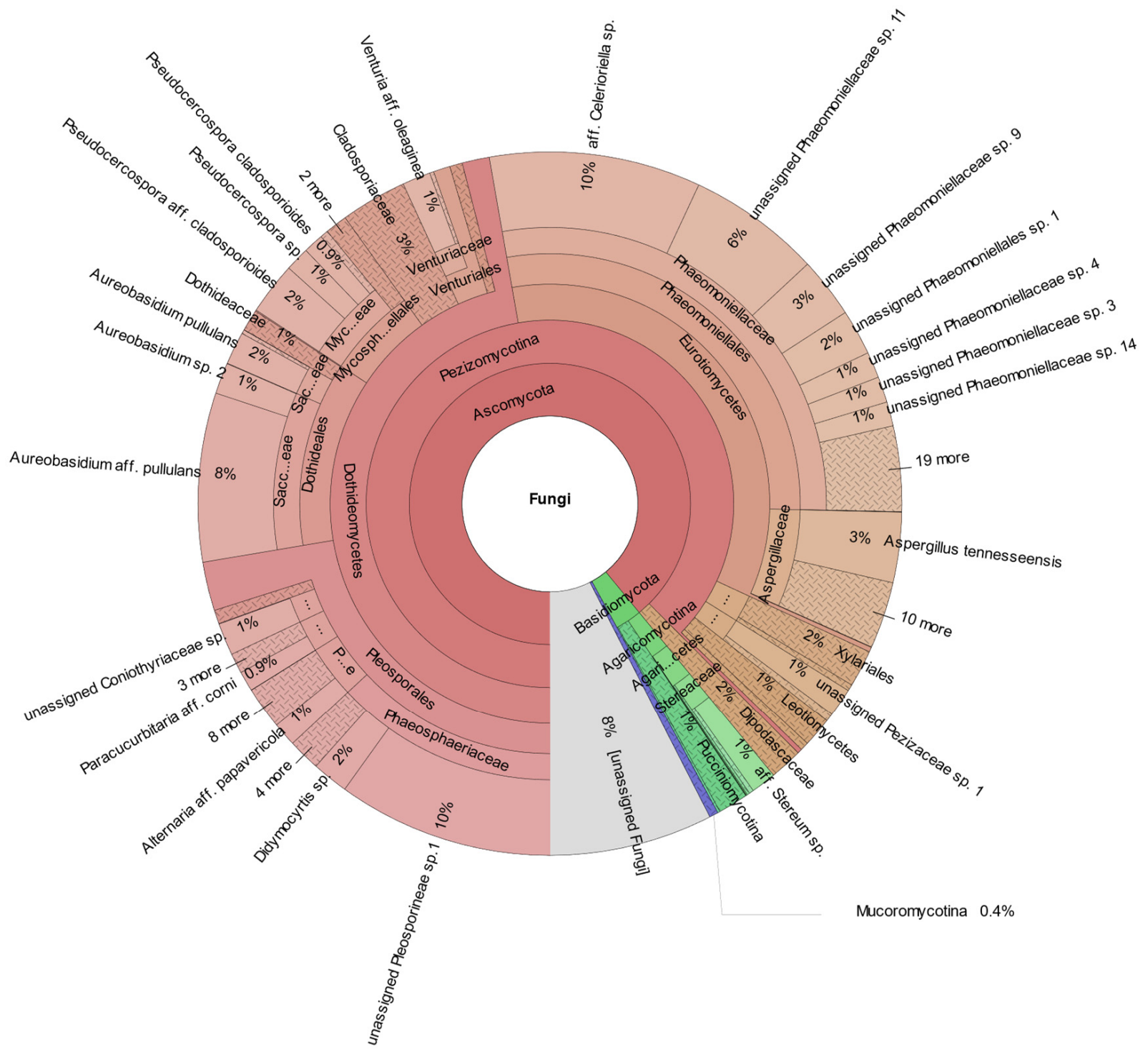

Figure 1. Krona chart showing the relative abundance of total fungi (endophytic and epiphytic), at the genus level, detected on leaves of olive trees of cvs. Cobrançosa and Madural. 
Regarding isolates identified at least at the genera level (expressed as total number of isolates and average number of isolates per tree), the most abundant identified taxa in the endophytic community (Figure 2a) were Pseudocercospora (9.6\%), Cladosporium (4.8\%) and Didymocyrtis (3.3\%). However, there were three abundant taxa that could not be assigned at the genus level (which are included in the label "Others", in Figure 2), two unassigned Phaeomoniellaceae species $(11.5 \%$ and $5.6 \%)$ and one unidentified fungus (8.1\%). Considering different cultivars, for cv. Cobrançosa, Pseudocercospora (with 13\%), Cladosporium (8\%) and Alternaria (7\%) were the most abundant identified genera. For cv. Madural, the identified genera Didymocyrtis (8\%), Pseudocercospora (7\%) and Venturia $(5 \%)$ were the most abundant. In relation to the epiphytic community (Figure 2b), Aureobasidium $(21 \%)$ was the most abundant taxon, followed by an unassigned Phaeosphaeriaceae species (19.4\%), Celeriorella (18.3\%), Aspergillus (6.5\%) and Penicillium (4.3\%). Taking into account the epiphytic community in each cultivar, the most abundant genera for cv. Cobrançosa were Aspergillus (16\%) and Penicillium (10\%), while for cv. Madural were Aureobasidium $(35 \%)$ and Celerioriella $(31 \%)$.

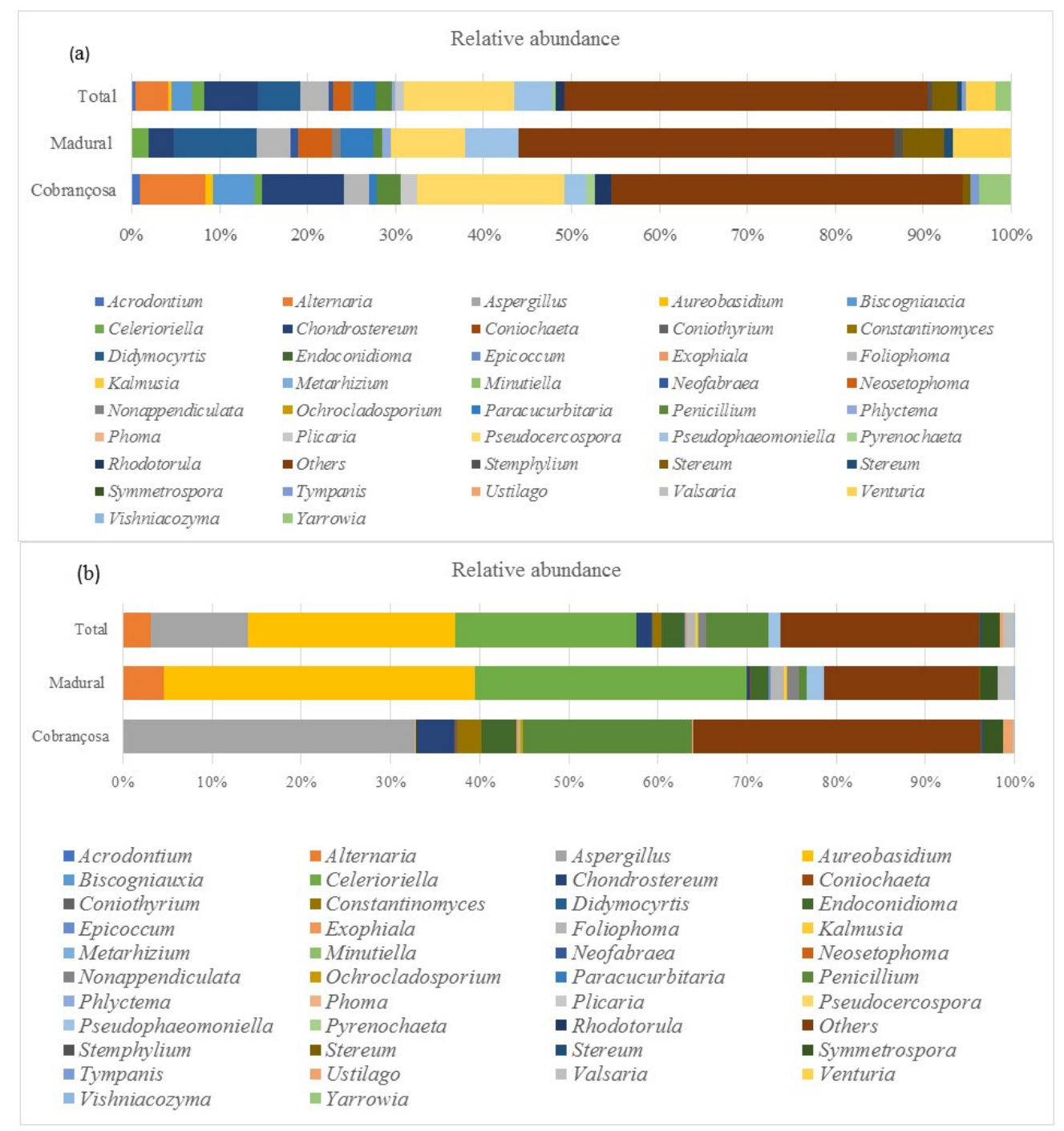

Figure 2. Relative abundances of genera from the (a) endophytic and (b) epiphytic communities associated with leaf tissues of Olea europaea L. (cvs. Madural and Cobrançosa). 


\section{Discussion and Conclusions}

This study provided some new insights into the fungal diversity composition of endophytic and epiphytic communities associated with leaves from olive trees cultivated in an organic orchard. It was shown that the epiphytic community is largely dominated by 2-3 abundant taxa (Aureobasidium, a Phaeosphaeriaceae unassigned species and Celeriorella), and it seems that the composition may differ between cultivar, at least regarding the more abundant taxa. On the other hand, for the endophytic community, the most abundant taxa were not so dominant and there is not an obvious discrepancy between the taxa composition in cvs. Cobrançosa and Madural. These patterns were already shown in previous studies on olive trees, in leaves and in other plant organs [8,9]. Furthermore, some abundant but unassigned species that are present in both endophytic and epiphytic olive tree leaf communities are likely to represent novel taxa, something that deserve further investigation. We prospect that the determination of indicator value indices should help to expose the preference/specificity of a set of fungal species with the most-resistant cultivar. Preliminary data from ecological diversity and multivariate statistical analyses (data not shown), however, indicate that the host plant (at cultivar level) had a negligible effect on the composition of the fungal communities of the leaves. On the other hand, they also highlight that Phaeomoniella, Pseudocercospora, Paracucurbitaria and two unidentified species are the five taxa that contributed the most to the differences between the endophytic and epiphytic composition. Future research needs to decipher these complex interactions between plants, fungi and pathogens, and assess their role in plant health.

Author Contributions: J.A.P. and P.B. conceived and designed the experiments; H.B., V.R. and D.M. performed the experiments; H.B., V.R. and P.B. analysed the data; J.A.P. and P.B. contributed with reagents, materials and analysis tools; V.R. and P.B. wrote the paper. All authors have read and agreed to the published version of the manuscript.

Institutional Review Board Statement: Not applicable.

Informed Consent Statement: Not applicable.

Acknowledgments: This work is supported by FEDER funds through the COMPETE (Operational Programme for Competitiveness Factors) and by National funds through the FCT (Foundation for Science and Technology) within the POCI-01-0145-FEDER-031133 (MicOlives) project. H.B. also acknowledges FCT for his «Verão com Ciência» fellowship.

Conflicts of Interest: The authors declare no conflict of interest.

\section{References}

1. Cacciola, S.O.; Faedda, R.; Sinatra, F.; Agosteo, G.E.; Schena, L.; Frisullo, S.; di San Lio, G.M. Olive anthracnose. J. Plant Pathol. 2012, 94, 29-44.

2. Besnard, G.; Terral, J.F.; Cornille, A. On the origins and domestication of the olive: A review and perspectives. Ann. Bot. 2018, 121, 385-403. [CrossRef] [PubMed]

3. International Olive Council. Available online: https:/ /www.internationaloliveoil.org/\#newsletter (accessed on 10 September 2020).

4. Talhinhas, P.; Loureiro, A.; Oliveira, H. Olive anthracnose: A yield-and oil quality-degrading disease caused by several species of Colletotrichum that differ in virulence, host preference and geographical distribution. Mol. Plant Pathol. 2018, 19, 1797-1807. [CrossRef] [PubMed]

5. Talhinhas, P.; Mota-Capitão, C.; Martins, S.; Ramos, A.P.; Neves-Martins, J.; Guerra-Guimarães, L.; Várzea, V.; Silva, M.C.; Sreenivasaprasad, S.; Oliveira, H. Epidemiology, histopathology and aetiology of olive anthracnose caused by Colletotrichum acutatum and C. gloeosporioides in Portugal. Plant Pathol. 2011, 60, 483-495. [CrossRef]

6. Moral, J.; Xaviér, C.J.; Viruega, J.R.; Roca, L.F.; Caballero, J.; Trapero, A. Variability in susceptibility to anthracnose in the world collection of olive cultivars of Cordoba (Spain). Front. Plant Sci. 2017, 8, 1892. [CrossRef] [PubMed]

7. Simeone, V.; Baser, N.; Perrelli, D.; Cesari, G.; El Bilali, H.; Natale, P. Residues of rotenone, azadirachtin, pyrethrins and copper used to control Bactrocera oleae (Gmel.) in organic olives and oil. Food Addit. Contam. 2009, 26, 475-481. [CrossRef] [PubMed]

8. Bacon, C.W.; White, J.F. Functions, mechanisms and regulation of endophytic and epiphytic microbial communities of plants. Symbiosis 2016, 68, 87-98. [CrossRef]

9. Landum, M.C.; do Rosário Félix, M.; Alho, J.; Garcia, R.; Cabrita, M.J;; Rei, F.; Varanda, C.M. Antagonistic activity of fungi of Olea europaea L. against Colletotrichum acutatum. Microbiol. Res. 2016, 183, 100-108. [CrossRef] [PubMed] 
10. Preto, G.; Martins, F.; Pereira, J.A.; Baptista, P. Fungal community in olive fruits of cultivars with different susceptibilities to anthracnose and selection of isolates to be used as biocontrol agents. Biol. Control 2017, 110, 1-9. [CrossRef]

11. Martins, F.; Pereira, J.A.; Bota, P.; Bento, A.; Baptista, P. Fungal endophyte communities in above-and belowground olive tree organs and the effect of season and geographic location on their structures. Fungal Ecol. 2016, 20, 193-201. [CrossRef]

12. Gomes, T.; Pereira, J.A.; Benhadi, J.; Lino-Neto, T.; Baptista, P. Endophytic and epiphytic phyllosphere fungal communities are shaped by different environmental factors in a Mediterranean ecosystem. Microb. Ecol. 2018, 76, 668-679. [CrossRef] [PubMed]

13. White, T.J.; Bruns, T.; Lee, S.; Taylor, J. Amplification and direct sequencing of fungal ribosomal RNA genes for phylogenetics. In PCR Protocols: A Guide to Methods and Applications; Innis, M.A., Gelfand, D.H., Sninsky, J.J., White, T.J., Eds.; Academic Press: New York, NY, USA, 1990; pp. 315-322.

14. Federhen, S. Type material in the NCBI Taxonomy Database. Nucleic Acids Res. 2015, 43, D1086-D1098. [CrossRef] [PubMed]

15. Vu, D.; Groenewald, M.; De Vries, M.; Gehrmann, T.; Stielow, B.; Eberhardt, U.; Al-Hatmi, A.; Groenewald, J.Z.; Cardinali, G.; Houbraken, J.; et al. Large-scale generation and analysis of filamentous fungal DNA barcodes boosts coverage for kingdom fungi and reveals thresholds for fungal species and higher taxon delimitation. Stud. Mycol. 2019, 92, 135-154. [CrossRef] [PubMed] 